\title{
Heat exchanger design studies for molten salt fast reactor
}

\author{
Uğur Köse ${ }^{1}$, Ufuk $\operatorname{Koç}^{1}$, Latife Berrin Erbay ${ }^{2}$, Erdem Öğ̈̈t ${ }^{3}$, and Hüseyin Ayhan ${ }^{1, *}$ \\ ${ }^{1}$ FİGES Engineering, R\&D Center, Nuclear Technology Department, 06690 Ankara, Turkey \\ 2 Eskişehir Osmangazi University, Mechanical Engineering Department, 26040 Eskişehir, Turkey \\ ${ }^{3}$ FİGES Engineering, Teknopark-İstanbul, Additive Manufacturing Systems Department, 34906 İstanbul, Turkey
}

Received: 15 February 2019 / Received in final form: 8 July 2019 / Accepted: 20 September 2019

\begin{abstract}
In this study, conceptual design for primary heat exchanger of the Molten Salt Fast Reactor is made. The design was carried out to remove the produced heat from the reactor developed under the SAMOFAR project. Nominal power of the reactor is $3 \mathrm{GWth}$ and it has 16 heat exchangers. There are several requirements related to the heat exchanger. To sustain the steady-state conditions, heat exchangers have to transfer the heat produced in the core and it has to maintain the temperature drop as much as the temperature rise in the core due to the fission. It should do it as fast as possible. It must also ensure that the fuel temperature does not reach the freezing temperature to avoid solidification. In doing so, the fuel volume in the heat exchanger must not exceed the specified limit. Design studies were carried out taking into account all requirements and final geometric configurations were determined. Plate type heat exchanger was adopted in this study. 3D CFD analyses were performed to investigate the thermal-hydraulic behavior of the system. Analyses were made by ANSYS-Fluent commercial code. Results are in a good agreement with limitations and requirements specified for the reactor designed under the SAMOFAR project.
\end{abstract}

\section{Introduction}

The power production from the thermal power plants is possible through a thermodynamic cycle. The heat produced in the core of a nuclear reactor by a fissionable fuel is transported into a coolant. Then, heat is transferred to the working fluid by using heat exchangers (HX). This thermodynamic cycle is mainly either Rankine or Brayton cycle. Molten Salt Reactors (MSRs) have gained importance and different initiatives have been brought. A sustainable secure nuclear future based on Thorium Molten-Salt Nuclear Energy Synergetics (THORIMS-NES) [1-5] and a conceptual design of a Stirling engine with the MSR reactor [6] are typical examples.

In MSRs, the heat transfer between the radioactive liquid fuel salt and the secondary salt or between this salt and the conversion working fluid is ensured by heat exchangers. In the MSRs, one of the most important equipment after the core is the heat exchanger. Therefore, the design of the heat exchangers for MSRs is a crucial task.

The number of heat exchangers varies depending on the design of the core, the number of loops, and the type of the power cycle. The primary loop and the secondary loop heat exchangers, preheaters, steam generators, after heaters, condensers and others are all different types of heat

\footnotetext{
* e-mail: huseyin. ayhan@figes.com.tr
}

exchangers with certain vital functions in the MSR cycle. They are the main components of the plant due to not only their functions and the numbers but also as their different conditions and tradeoffs depending on the location and connections in the main cycle.

The heat exchanger design is also strictly subjected to change with the properties of fluids flowing through the heat exchanger. The type of the coolant and working fluid should be determined in advance. In the MSRs, the principle liquid fuel is preferred as a molten salt consisting of eutectic salts and operating at temperatures of 600 $800{ }^{\circ} \mathrm{C}$ including $\mathrm{LiF}-\mathrm{BeF}_{2}-\mathrm{ThF}_{4}$ for the case of thorium after many researches. The problem is the thermo-physical properties of these eutectics. When $\mathrm{LiF}-\mathrm{BeF}_{2}-\mathrm{ThF}_{4}$ is considered, it is found that two different mole percentages can be used. In the first salt, the mole percentages of LiF$\mathrm{BeF}_{2}-\mathrm{ThF}_{4}$ are $72.7-15.7-11.6$ whereas in the second one, percentages will be 70.11-23.88-6.01 [7]. Such a small difference causes dramatic changes in the properties. For example, between 553 and $673^{\circ} \mathrm{C}$, the viscosity of the first salt varies between 14.1 and $7.74 \mathrm{cp}$. Whereas the viscosity of the second salt at the temperatures between 557 and $653^{\circ} \mathrm{C}$ varies from 12.59 to $7.30 \mathrm{cp} \mathrm{[7].} \mathrm{When} \mathrm{the} \mathrm{viscosity} \mathrm{is}$ concerned, the 3rd and 4th degree polynomials exist for these salts, respectively. This gives an idea how difficult is the design of a heat exchanger system in terms of such unique properties of salts. The properties of fluids therefore indicate an important and serious step in the design study. 
The main design purpose is to supply the exact heat transfer at a given time duration during operation. The total heat transfer area between the fluids, the overall heat transfer coefficient and temperature differences of fluids in both sides are the main parameters to be known on one side and to be determined on the other side. They are mutually dependent items.

For MSFR, that needs much larger heavy elements inventory than thermal MSR, there is an incentive to minimize the fuel salt volume, a limited fraction of which being in the heat exchangers. Therefore, the rate of heat transfer in the heat exchanger should be augmented and hence compact structures with high heat transfer areas per unit volume are necessary. However, enhancement in heat transfer will adversely affect pressure loss, which is related to pump design.

As it can be deduced from these explanations, the design of heat exchangers is critical. The design studies of the heat exchangers obviously require attention for complete and successful operation and it is needed that design parameters must be strictly defined to get most efficient heat transfer through the MSR. The previous efforts on the heat exchanger design for MSRs are summarized first in the following section. Then the design studies of the primary heat exchangers of Molten Salt Fast Reactor (MSFR) are carried out by FIGES under the SAMOFAR Project are going to be presented.

\section{Historical development of the HXs for MSRs}

The number and size of heat exchangers in MSR plants depend on the physical properties of the fluids, power level and the type of the thermodynamic cycle preferred. In the Brayton cycles, two or three to eight intercooling stages are used, which means that there are many HXs as in the multireheat steam circulations in Rankine cycle.

The thermodynamics of MSRs is well established since the first studies carried by Oak Ridge National Laboratory (ORNL) in 1950s. The design experience on the HXs used in MSRs lies to the initial development of MSRs to provide a heat source to a jet engine in the US Nuclear Aircraft Development Program (NAP) in 1950s (or it is mentioned as Aircraft Nuclear Propulsion - ANP Program [8]). Following the cancellation of the aircraft program, MSR was investigated between 1960s and 1970s up to the cancellation of the program by US ultimately. Due to over 20-yr effort, HX design studies of ORNL deserves attention before practicing the advanced design studies for MSFR.

The HXs which are used in the Homogeneous Reactor Test (HRE-2) at ORNL [9] were manufactured by considering typical shell \& tube HX design principles. For the primary and secondary loops, eight fuel to sodium HXs and sodium to steam HXs were all shell \& tube type. In order to get an idea about the design, it is better to give some numerical values for some parameters. The main characteristics of the HRE-2 steam generators had the heat transfer area of $44.6 \mathrm{~m}^{2}$ with the rate of heat transfer of $5000 \mathrm{~kW}$. The tube side diameter of $0.009525 \mathrm{~m}$ was used with the velocities of 20.42 and $3.44 \mathrm{~m} / \mathrm{s}$ on the shell side and tube side, respectively. The inlet and exit temperatures for shell and tube sides were $82.2-443.9^{\circ} \mathrm{C}$ and 256.9 $300.0^{\circ} \mathrm{C}$, respectively. The shell \& tube steam generators in HRE-2 were thermal cycled with diphenyl as the heating medium. HRE-2 spare steam generator [9] contained eighty-eight 5/8 in OD, 0.095 in thick, type-347 stainless-steel tubes having multiple U-bends.

A salt-to-gas primary HX design study was carried [10] for determining the problems and the effects of varying $\mathrm{HX}$ tubing size, coolant inlet temperature, coolant pressure level, allowable salt pressure drop and uranium enrichment of the molten salt. For this design study, a reactor of 640 MWth and electrical output of 275 MW was considered. The type of the HX was a cross, countercurrent flow arrangement with molten salt having four serpentine passes across the gas stream. Inconel was the material for tubing and circumferential fins.

Two experimental reactors were built and successfully operated. These were the Aircraft Reactor Experiment (ARE), the first MSR with 2.5 MWth, and the Molten Salt Reactor Experiment (MSRE), with 8 MWth. MSRE was a first experimental step to study a large Molten Salt Breeder Reactor (MSBR) and should have been followed by the Molten Salt Breeder Experiment (MSBE), a fullscale model of the MSBR used at 100-150 MWth $[8,11]$ that has never been built. Some test loops with molten salts were operated for hundreds of thousands of hours. Materials of construction were code qualified to $750^{\circ} \mathrm{C}$ and a detailed conceptual design of a 1000 MWe MSBR was developed. The history of HXs for MSRs is parallel to those efforts.

The HX in the primary fuel circuit of Molten Salt Reactor Experiment (MSRE) of 10 MWth limited to about 7.5 MWth was designed in 1961, fabricated in 1963 and installed in 1964. After some modifications, the HX has been operated for approximately $14000 \mathrm{~h}$ with molten salt temperatures from 537.8 to $662.8^{\circ} \mathrm{C}$ without any leakage and no change in the performance [12]. The HX of a shell \& tube type with U-tube configuration was chosen since it is the best design which satisfied the requirements and minimized the thermal expansion problems. The fuel flows through the shell side of the primary HX and the coolant salt circulates at the tube side. HX was tested with water but there were excessive vibrations and pressure drop. It was noted that [12] to alleviate the tube vibrations and lower the shell side pressure drop, 4 outermost U-tubes and 4 associated tie bars were removed and plugs were welded into the 8 resulting tube stub ends, and into all the resulting holes in the baffle plates since the U-bends vibrated quite severely.

The heat-exchange system for one conceptual $1000 \mathrm{MWe}$ MSBR has been studied [13]. A modular-type design having four separate but identical reactors with their own salt circuits was used by employing a two-region fluid-fuel concept in which fissile materials were in the core and fertile material was in the blanket streams. Five types of HXs were mentioned in each loop, namely, one primary fuel salt to coolant salt exchanger, one blanket salt exchanger, four boiler superheater exchangers, two steam re-heater exchangers, and two reheat steam preheaters to transfer the heat in the fuel and blanket salts to the coolant salt and from the coolant salt to the 
supercritical fluid. They were all designed as shell \& tube HXs as two-pass vertical exchangers with disk and doughnut baffles.

In the units for a 1000 MWe MSR plant [14], there were a boiler superheater and two reheaters designed as shell \& tube HX. Besides many different attempts to design boilers for MSR plants with some serious disadvantages have been made, a reentry tube boiler type was proposed to satisfy all the major requirements for the steam generators of liquid metal and MSR power plants. The salt was $\mathrm{NaBF}_{4}$, which mainly determined the tube length required. It was added that plant layout studies in a conceptual design for the net electrical output of $1000 \mathrm{MW}$ favored the use of six steam generators each coupled to one of six fuel-to- $\mathrm{NaBF}_{4}$ HXs in the Rankine cycle. Therefore, the design was an illustrative for the analysis of the full-scale steam generator. In this design, the thermal resistance of the inner tube wall at the lower end was increased by using double-walled tube with a gap that is going to be vented and filled with steam.

The steam generator with 349 parallel vertical U-shaped HX with one shell pass and one tube pass was simulated [15] on an analog computer to understand the dynamic responses of the components. For the dynamic analysis, a single water tubular channel surrounded by a salt annular channel was taken as a model. The design studies of HXs should obviously include such dynamic analysis.

A U-tube HX as one of the six fuel to inert salt HXs in a $2200 \mathrm{MW}$ th reference design reactor was analyzed [16]. The tube bundle had the tubes in an equilateral triangular layout and the fuel salt flows axially around the tubes on the shell side and the inert salt in counter flow inside the tubes. The analyses were concentrated on the parametric effects to the HX design to optimize the system design. In order to minimize the fuel inventory in the HX, which is a dependent variable of major interest, tube size is decreased, the fuel pressure drop is increased, it is decided that the salt can be FLiNaK instead of $\mathrm{NaBF}_{4}$, and the temperature difference between the fuel and inert salt is increased.

In MSR plants, heat exchangers of the shell \& tube type have been distinguished so far. The well developed technology and widely used standards of the shell \& tube type HXs are the main reasons for their preferability. Mainly conventional shell \& tube with U-tubes and shell \& tube with U-tubes in a U-shaped casing for supercritical pressure steam were proposed but the excessive temperature difference between salt and steam, the possibility of freezing of salt and unstable boiling were major problems in these types $[14,17]$. The temperature differences between inlet and outlet fluid during steady-state operation is limited but large temperature changes may occur at transient cases. Therefore, thermal stresses become a major design consideration too.

The main disadvantages of a shell and tube heat exchanger are low heat transfer efficiency, low heat transfer surface area density. Besides, the main advantages of plate type heat exchanger are less erosion-corrosion issues compared to shell and tube heat exchanger, wide choice of materials (important for corrosion and erosion of the salts), low salt inventory, high turbulence and true counter flow lead to an efficient heat transfer [18,19]. In this study, it has been focused on the plate-type heat exchanger design to overcome these problems.

By looking at these historical design efforts for the design of HXs for molten salt reactors, the HXs were specified the existing technology and under the Standards of Tubular Exchanger Manufacturers Association (TEMA) and ASME. Today, technology presents well developed alternative compact types, like parallel plate HXs. It is obviously deduced that many critical parameters and the relations between these parameters must be strictly defined and considered to get an optimized system design as a whole. For the system designed, all boundary and operation conditions were limited and studies were carried out. All variables that affect the performance of the system were studied parametrically.

\section{Design studies for SAMOFAR project}

In this section, the design methodology and the proposed type will be explained. The type of HX is determined according to the design criteria for the adopted conceptual MSFR. The MSFR, which is designed under SAMOFAR project, has the thermal capacity of $3000 \mathrm{MW}$. There are 16 HX located outside of the cylindrical reactor [20-23]. Therefore, the thermal capacity of each heat exchanger is approximately $190 \mathrm{MW}$. Since a compact heat exchanger is intended, it has been focused on plate type heat exchangers. Moreover, fuel residence time will be short, pressure drop amount will be small and also the maintenance procedure is easier for the plate type HX. The design of the heat exchanger plates was carried out in a flat and corrugated form. Analyses were conducted in such a way that there were countercurrent flow for both designs. Since the circulation time of the fuel salt in the system should be kept as short as possible [21,22], the single-pass heat exchanger design, rather than the multi-pass, is considered.

\subsection{Design procedure}

In the heat exchanger design process, there are several important requirements such as thermal-hydraulic design, mechanical design, material selection, manufacturability, maintenance and safety. The heat exchanger is expected to meet certain criteria such as thermal capacity, hydraulic behavior and material strength, especially, and to have the most suitable form such as compactness, manufacturability and maintainability. This study focuses on the thermalhydraulic analyses of the heat exchanger. The design procedure created for the study is given in Figure 1. Oneway arrow represents forward process and two-way arrow represents iterative process. 3D CFD results were used to correlate the dimensionless model (0D Model). 3D CFD studies and mechanical analyses provide lots of feedback to each other.

In the flat plate design, parameters that affect the performance of the system such as channel spacing, plate thickness, fluid inlet velocities and inlet temperatures have been investigated by using a 0D Model with the solver 


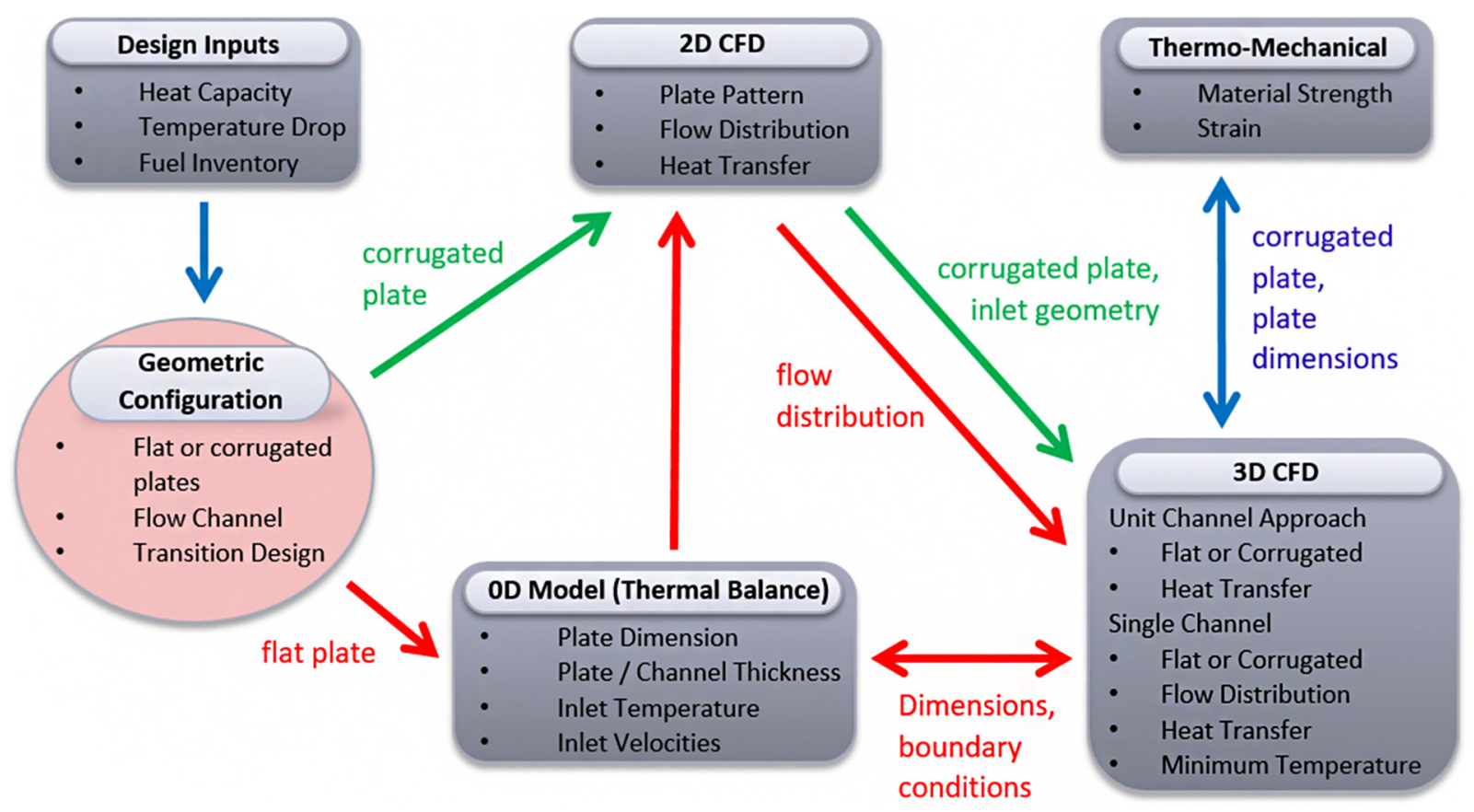

Fig. 1. Design procedure.

created in MATLAB platform. For the decision of geometric configuration, 2 and 3 dimensional (2D\&3D) computational fluid dynamics (CFD) analyses were performed. The flow distribution and thermal performance of the system were examined in detail. In the 2D study, analyses were performed to ensure that the fluids were uniformly and evenly distributed within the channel. Geometric parameters determined in 0D model were used in 2D studies. In 2D analyses, collector locations, entrance geometry type and flow separator position and dimensions were studied. After achieving the ideal combinations, 3D studies were performed using $2 \mathrm{D}$ CFD results and $0 \mathrm{D}$ Model parameters like plate dimensions and inlet conditions. In 3D CFD studies, the thermal behavior of the system was investigated in detail. Bulk temperatures, local minimum temperatures and temperature gradient distributions were investigated.

In the corrugated plate design, the effect of design parameters such as groove depth, groove opening, channel width and fluid velocities were investigated by using 2D CFD analyses. Then the detailed 3D CFD analyses were performed to investigate the flow characteristics as well as the thermal behavior.

\subsection{Preliminary studies}

For heat exchanger design, a program (script) was written in MATLAB and the user interface was prepared to determine the geometric configuration. This program provides a dimensional comprehension of the desired logarithmic temperature difference in a flat plate without separators. The model was initially considered ideal. For example, collectors are properly positioned, flow is uniformly distributed and inlet effects are ignored. With the outputs of this program, the dimensions of the flat plate were roughly decided and the CFD studies were continued. In line with the outputs from MATLAB, 3D unit-channel CFD analyses were performed on a flat plate with no brackets by accepting that the flow is evenly distributed. The CFD results for bulk temperatures and system height were compared with the results of the MATLAB program. Considering the differences, the 0D Model was corrected by adjusting the correlations or revising the assumptions. After ensuring consistency between MATLAB code and CFD results, the channel parameters and boundary conditions for a flat plate were studied on the code and the operating range for an ideal heat exchanger was determined.

After determining the working range for heat exchanger design, feasibility studies were performed on this design. The 2D CFD analyses were performed for suitable cases. Firstly, inlet and outlet collectors were positioned. Several configurations were studied for an ideal location. Following this study, 2D and 3D CFD analyses were carried out by placing separators in various numbers, thicknesses and positions in the plate in order to ensure the reproducibility and even flow distribution. After deciding the placement of collectors and separators, the velocity and pressure distribution profiles of fluids in the plate were examined. In particular, the pressure distribution profiles give information about which channel in the plate should be narrow and which should be wider. The heat exchanger geometry has been optimized by adjusting with the separator locations and the channels. CFD studies were performed for several plate configuration to achieve best hydraulic performance. Velocity distributions of each configuration are illustrated in Figure 2.

For this design study, stagnant flow or highly vortex flow conditions were avoided. In both conditions, uniform temperature distribution will not occur and it may cause 


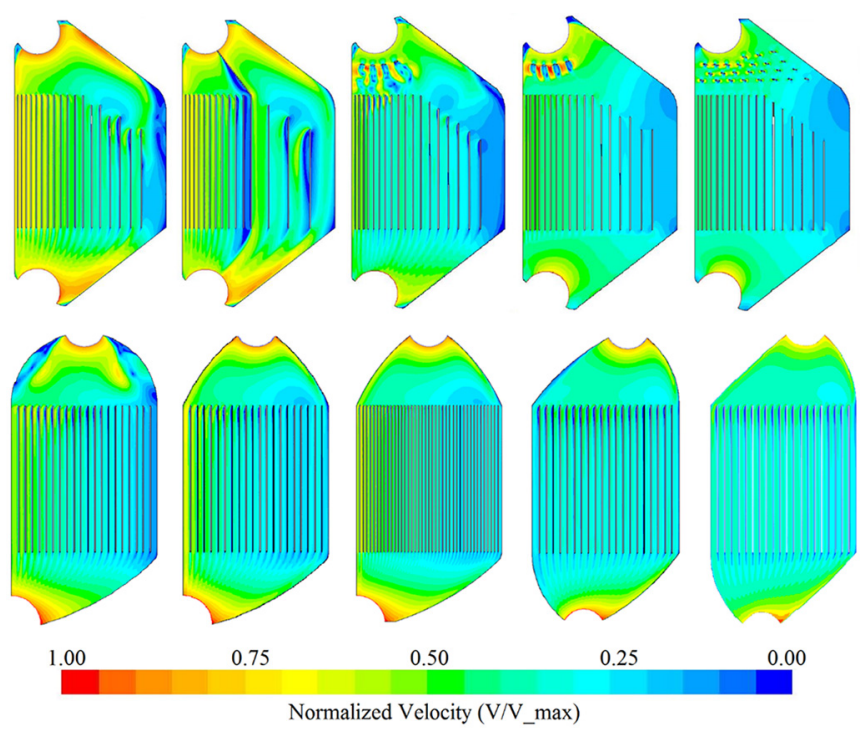

Fig. 2. Velocity distribution of $2 \mathrm{D}$ parametric studies for flat plate (plate height is about $1.5 \mathrm{~m}$ and width is $0.7 \mathrm{~m}$ ).

local freezing. Besides, the uniformly distributed mass flux is preferred in this study to control the temperature drop and to obtain a smaller temperature gradient in all directions. As can be seen from Figure 2, there is a uniformly distributed velocity profile along the channel cross-section in the final design.

In addition to the flat plate geometry, design studies were carried out for the corrugated plate. 2D CFD analyses were performed for corrugated plate. The distribution of the flow within the channels and the temperature behavior were investigated. Different combinations of channels have been studied and the effect over the flow distribution and temperature profile is examined. Groove depth, groove opening, channel width and fluid velocities were changed parametrically. Figure 3 shows the velocity distribution and temperature profiles of several geometric configurations. The whole system is shown to clearly see the temperature change amounts, while a small part of the system is shown to see in detail the velocity behavior. In all cases, the mass flow rate is the same as each other.

As seen in the sub-figures, as grove depth (a) decreases, pressure drop amount decreases; however, temperature difference decreases too. In that case velocity magnitude is at low level within the channels. On the other hand, as grove opening (b) decreases, heat transfer amount increases; however, pressure drop amount increases too. It should be noted that, to reach the required temperature drop amount, the height of the HX will be different in all cases. So in the case of a smaller grove depth, the system height will increase and also pressure drop amount will increase too. Besides, in the case of smaller grove opening, local freezing may occur due to the stagnant flow near the plate wall. However, this effect may prevent the plate from the salt corrosion.

After 2D studies, 3D CFD analyses were performed for a small part of this geometry. The curved structure of this geometric design made it very challenging to create the mesh model. Velocity and temperature distribution profiles were also investigated with $3 \mathrm{D}$ CFD analyses. For the corrugated design, there is no spacer or supporter between the plates. Since the grooves contact each other in the opposite direction, they serve as supporter at the same time. However, stagnation regions will occur around these contact points. Due to the occurrence of stagnant regions (and also freezing regions), flat plate model is adopted as design geometry.

\subsubsection{Zero-dimensional modeling}

Heat exchanger geometry is divided horizontally by a number of elements (nodes). The expected fuel temperature drop $\left(\Delta T_{\text {fuel }}\right)$ is distributed to the elements so that the temperature of each element will change as $\Delta T_{\text {node }}$ ( $\Delta T_{\text {fuel }} / \#$ of elements). In other words, each horizontal element is not equal in height, but $\Delta T_{\text {node }}$ between each element are the same. In this way, the value of the fuel temperature in each element can be clearly known which led to easier calculations, however only the inlet node temperature of the coolant is known. The heat from each element of the fuel channel is transferred to the coolant channel.

The energy that the element has is transferred via conduction and convection heat transfer to the neighboring channel. In order to achieve energy balance in the system, the heat transferred from the fuel channel, the heat received by the coolant channel, and the overall heat transfer must be equal to each other. Therefore:

$$
\dot{m}_{f} c_{p, f} \Delta T_{f}=\dot{m}_{c} c_{p, c} \Delta T_{c}=U A_{T} \Delta T_{l m}=Q
$$

equality must be provided for all neighboring nodes. Where $Q$ is the total heat rate, $\dot{m}$ is the mass flow rate, $c_{p}$ is the specific heat capacity, $\Delta T$ is the temperature difference, $\Delta T_{l m}$ is the logarithmic mean temperature difference, $A_{T}$ is the total heat transfer surface area, and $U$ is the overall heat transfer coefficient. Lower indices $m, f$ and $c$ represent the material, fuel and coolant salt, respectively.

The logarithmic mean temperature difference is defined as,

$$
\Delta T_{l m}=\left(\Delta T_{1}-\Delta T_{2}\right) / \ln \left(\Delta T_{1} / \Delta T_{2}\right)
$$

where $\Delta T_{1}=T_{f, \text { inlet }}-T_{c, \text { outlet }}$ and $\Delta T_{2}=T_{f, \text { oulet }}-T_{c, \text { inlet }}$. The overall heat transfer coefficient is calculated as,

$$
\frac{1}{U}=\frac{1}{h_{f}}+\frac{t_{m}}{k_{m}}+\frac{1}{h_{c}}+R_{f m}+R_{c m}
$$

where $h$ represents the convection heat transfer coefficient and it can be calculated using several correlations such as the original Dittus-Boelter correlation or Gnielinski correlation [24]. $k, t_{m}$ and $R$ are the heat conduction coefficient, material thickness and the thermal resistance, respectively. Lower indices $f m$ and $\mathrm{cm}$ represent the fuel to material interface and coolant salt to material interface, respectively.

So, using equation (1), the unknown temperature of each coolant nodes can be calculated with starting from the coolant inlet. The element heights which can give the 

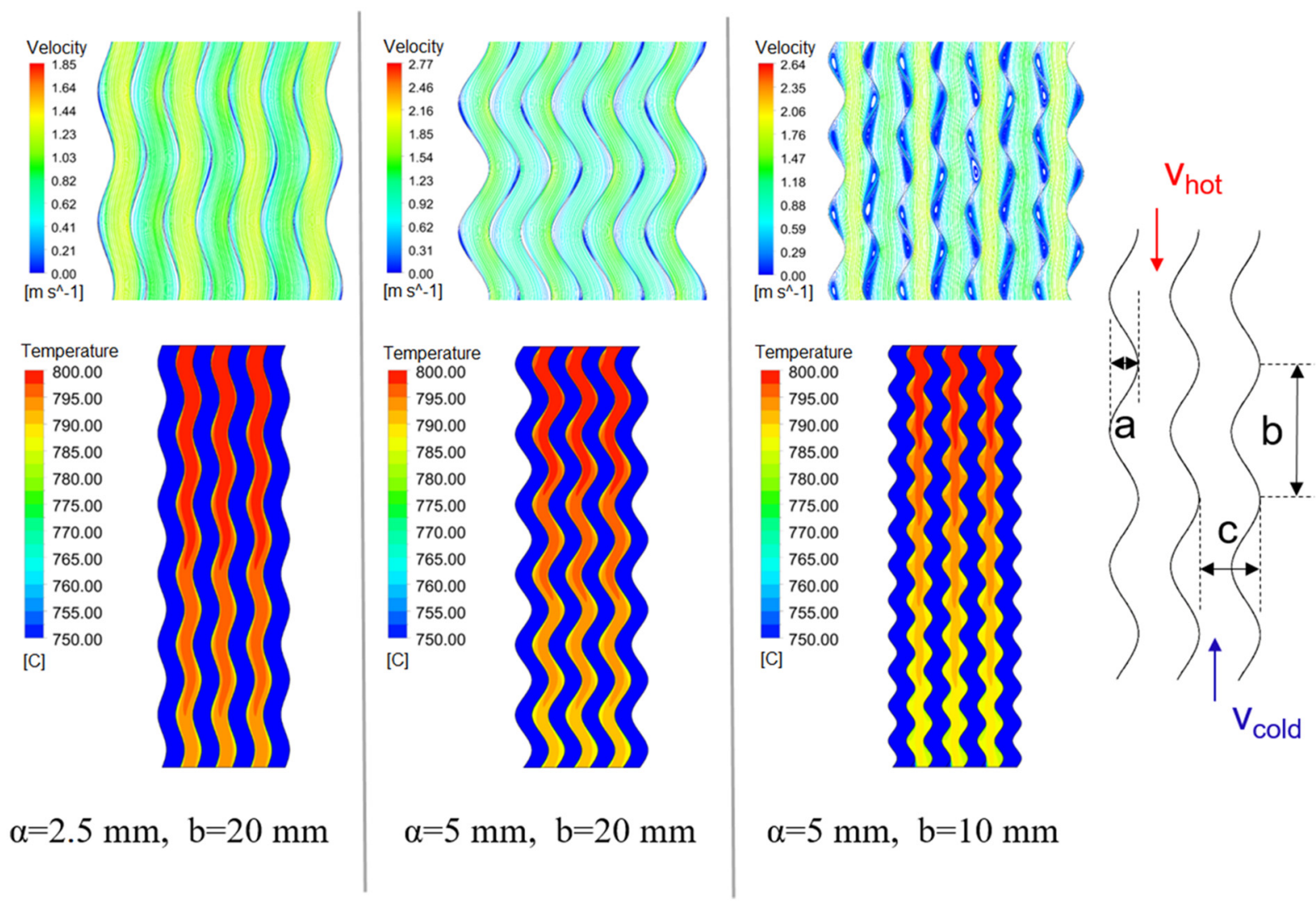

$\alpha=5 \mathrm{~mm}, \quad b=10 \mathrm{~mm}$

Fig. 3. Velocity distribution and temperature profiles of $2 \mathrm{D}$ parametric studies for corrugated plate.

desired temperature drop in the elements are also calculated one by one during the calculations. So the total height of the HX unit will be calculated.

Then, using the calculated values such as height, thermo-physical properties, and hydraulic properties of the nodes, the pressure drop $(\Delta p)$ of the fuel and coolant channels are calculated using,

$$
\Delta p=f * \frac{H}{D_{h}} * \rho * \frac{V^{2}}{2}
$$

where $H, D_{h}, \rho$ and $V$ represent height, hydraulic diameter, density and velocity, respectively. $f$ represents the Darcy friction factor and it can be calculated using the SwameeJain equation, which is the open form of the ColebrookWhite correlation for the rectangular ducts as,

$$
f=1.325\left[\ln \left(\frac{\in / D_{h}}{3.7}+\frac{5.74}{R e^{0.9}}\right)\right]^{-2}
$$

where $\in$ is the pipe surface roughness and $R e$ is the Reynolds number.

\subsubsection{CFD modeling}

The flow regime in both fuel and the salt channel is turbulence. So, in CFD analysis, the turbulence effect was taken into account with the $\mathrm{k}-\varepsilon$ (realizable) model. The wall effect is treated with Enhanced Wall Treatment option for solid surfaces where the wall boundary condition is applied.
Viscous heat effects were also included in the analysis. The "Coupled" algorithm was used for pressure-velocity coupling. The discretization methods were selected as "Presto" for pressure, "Quick" for energy and "Second Order" for other terms.

Fluid velocities and temperature conditions were used for inlet boundaries. Simulations were performed for one plate and neighboring half cannels. Symmetry boundary conditions were used for half channel interfaces. Residuals as a convergence criteria were adopted as $10^{-4}$ for all variables.

In the 2D CFD analyses map mesh is used. The total mesh number is about 1 million and $y+$ value is less than 2 in this models. In 3D CFD models cubic (hex) mesh elements are used. Edge-Sizing and Bias-Factor are defined for each side of the middle portion of the lower channelforming plates. The purpose of using these methods is to analyze the thermal-hydraulic effects better by giving a more frequent cubic mesh to the transition regions between the fuel, material and coolant. This is so important for the conjugated heat transfer calculation. In addition, the sweep method was used in the whole model in order to ensure the sufficient orthogonal quality and skewness values of the mesh elements. A total of 15-20 million mesh elements were used in 3D CFD calculations. Also $\mathrm{y}+$ value is less than 2 in $3 \mathrm{D}$ studies.

Mesh sensitivity analyses was performed for 3D CFD calculations. Some of the monitored values are listed in Table 1 . The terms $n_{f c h}, n_{p}$ and $n_{a x}$ represent the number of divisions of flow channels (both for fuel and coolant), plate 
Table 1. Monitored results for mesh sensitivity analyses.

\begin{tabular}{lllllllll}
\hline$n_{f c h}$ & $n_{p}$ & $n_{a x}$ & $T_{f o}\left({ }^{\circ} \mathrm{C}\right)$ & $T_{c o}\left({ }^{\circ} \mathrm{C}\right)$ & $T_{f, \min }\left({ }^{\circ} \mathrm{C}\right)$ & $\Delta P_{f}(\mathrm{bar})$ & $\Delta P_{c}(\mathrm{bar})$ & $W_{c h}(\mathrm{MW})$ \\
\hline 16 & 10 & 200 & 664.6 & 598.5 & 615.8 & 2.66 & 2.13 & 0.53 \\
24 & 10 & 200 & 665.0 & 598.4 & 616.0 & 2.67 & 2.17 & 0.53 \\
32 & 10 & 200 & 665.0 & 598.4 & 616.0 & 2.67 & 2.17 & 0.53 \\
24 & 4 & 200 & 665.0 & 598.4 & 615.5 & 2.67 & 2.17 & 0.53 \\
24 & 8 & 200 & 665.0 & 598.4 & 615.9 & 2.67 & 2.17 & 0.53 \\
24 & 10 & 200 & 665.0 & 598.4 & 616.0 & 2.67 & 2.17 & 0.53 \\
24 & 10 & 50 & 664.9 & 598.4 & 614.8 & 2.67 & 2.18 & 0.53 \\
24 & 10 & 100 & 664.9 & 598.4 & 615.4 & 2.67 & 2.18 & 0.53 \\
24 & 10 & 200 & 665.0 & 598.4 & 616.0 & 2.67 & 2.17 & 0.53 \\
24 & 10 & 500 & 665.1 & 598.3 & 616.0 & 2.66 & 2.17 & 0.53 \\
\hline
\end{tabular}

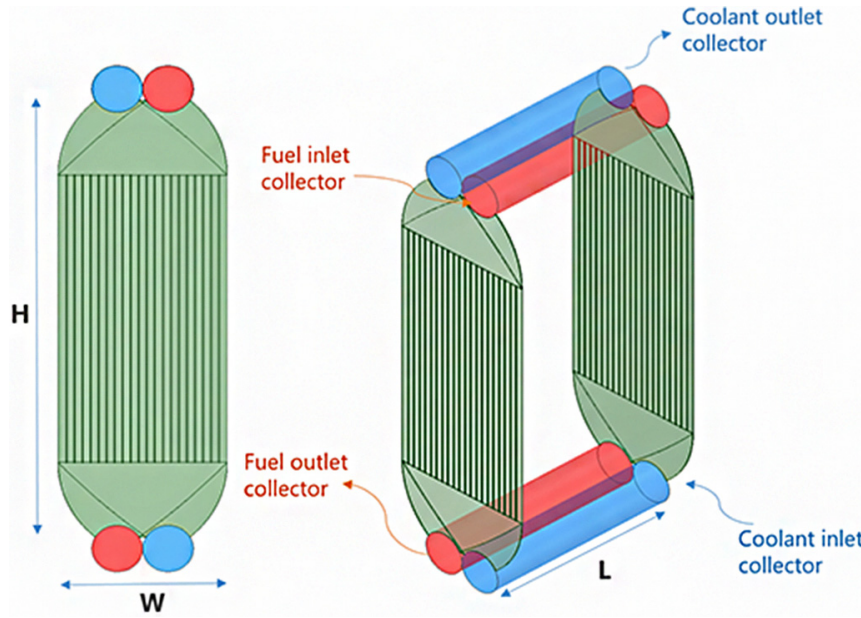

Fig. 4. Schematic view of the selected HX design with the collectors $(\mathrm{H}=$ height, $\mathrm{W}=$ width, $\mathrm{L}=$ length of the $\mathrm{HX})$.

and vertical direction, respectively. For all condition, outlet bulk temperatures, local minimum fuel temperature, pressure drop amounts and heat transfer amount are checked. According to the results of sensitivity analysis, the case of $n_{f c h}=24, n_{p}=10$ and $n_{a x}=200$ was selected as the most suitable mesh structure of the geometry and used in all cases.

\subsection{Conceptual design for MSFR}

According to the findings from CFD studies, the final form and geometric design is selected for HX of MSFR. The final geometric configuration of the plate type HX is shown in Figure 4. For the final design, 3D CFD analyses were performed with the boundary and operating conditions presented in the EVOL project report [20]. The reference concept of MSFR is designed for a nominal power of 3 GWth, with a salt temperature rise preliminary fixed at $\Delta T=100{ }^{\circ} \mathrm{C}[20,25]$. Therefore, there must be a temperature drop of $100^{\circ} \mathrm{C}$ in the fuel salt channel of HX. It is also stated that the fuel and coolant salt inlet temperatures should be around 800 and $490^{\circ} \mathrm{C}$, the fuel and coolant inlet velocities should be around $2-2.5 \mathrm{~m} / \mathrm{s}$ and $5-5.5 \mathrm{~m} / \mathrm{s}$, respectively [25].
Table 2. Boundary conditions of the HX.

\begin{tabular}{ll}
\hline Parameters & Value \\
\hline Fuel inlet temperature & $\sim 750^{\circ} \mathrm{C}$ \\
Coolant inlet temperature & $\sim 560^{\circ} \mathrm{C}$ \\
Fuel inlet velocity & $\sim 5 \mathrm{~m} / \mathrm{s}$ \\
Maximum fuel velocity in the channel & $\sim 2.5 \mathrm{~m} / \mathrm{s}$ \\
Coolant inlet velocity & $\sim 10 \mathrm{~m} / \mathrm{s}$ \\
Maximum coolant velocity in the channel & $\sim 5 \mathrm{~m} / \mathrm{s}$ \\
\hline
\end{tabular}

Table 3. Resulting values of the HX.

\begin{tabular}{ll}
\hline Parameters & Value \\
\hline Plate thickness & $2 \mathrm{~mm}$ \\
Seperator thickness & $2 \mathrm{~mm}$ \\
Seperator height & $\sim 1.3 \mathrm{~m}$ \\
Fuel channel thickness & $2 \mathrm{~mm}$ \\
Coolant channel thickness & $2-4 \mathrm{~mm}$ \\
Collector diameter & $0.21 \mathrm{~m}$ \\
Fuel outlet temperature & $\sim 675^{\circ} \mathrm{C}$ \\
Temperature drop in HX & $\sim 75^{\circ} \mathrm{C}$ \\
Coolant outlet temperature & $\sim 620^{\circ} \mathrm{C}$ \\
Minimum temperature at fuel channel & $\sim 620^{\circ} \mathrm{C}$ \\
HX dimension (H $\times$ L $\times$ W) & $\sim 2.0 \times 1.5 \times 0.7 \mathrm{~m}$ \\
Pressure drop in fuel channel & $\sim 3 \mathrm{bar}$ \\
Pressure drop in coolant channel & $\sim 5 \mathrm{bar}$ \\
Total fuel volume in 16 HX & $\sim 6 \mathrm{~m}^{3}$ \\
(HX and Collectors) & \\
\hline
\end{tabular}

Many different geometric and thermal-hydraulic design studies have been carried out in order to achieve $100^{\circ} \mathrm{C}$ temperature drop with these boundary conditions. The degree to which these studies meet the design criteria is examined. The design criteria are particularly focused on the criteria such as the height and width of the heat exchanger, the volume of the fuel salt, the amount of heat transferred, minimum fuel temperature, temperature drop of fuel salt and the pressure drop for fuel and coolant channels. 

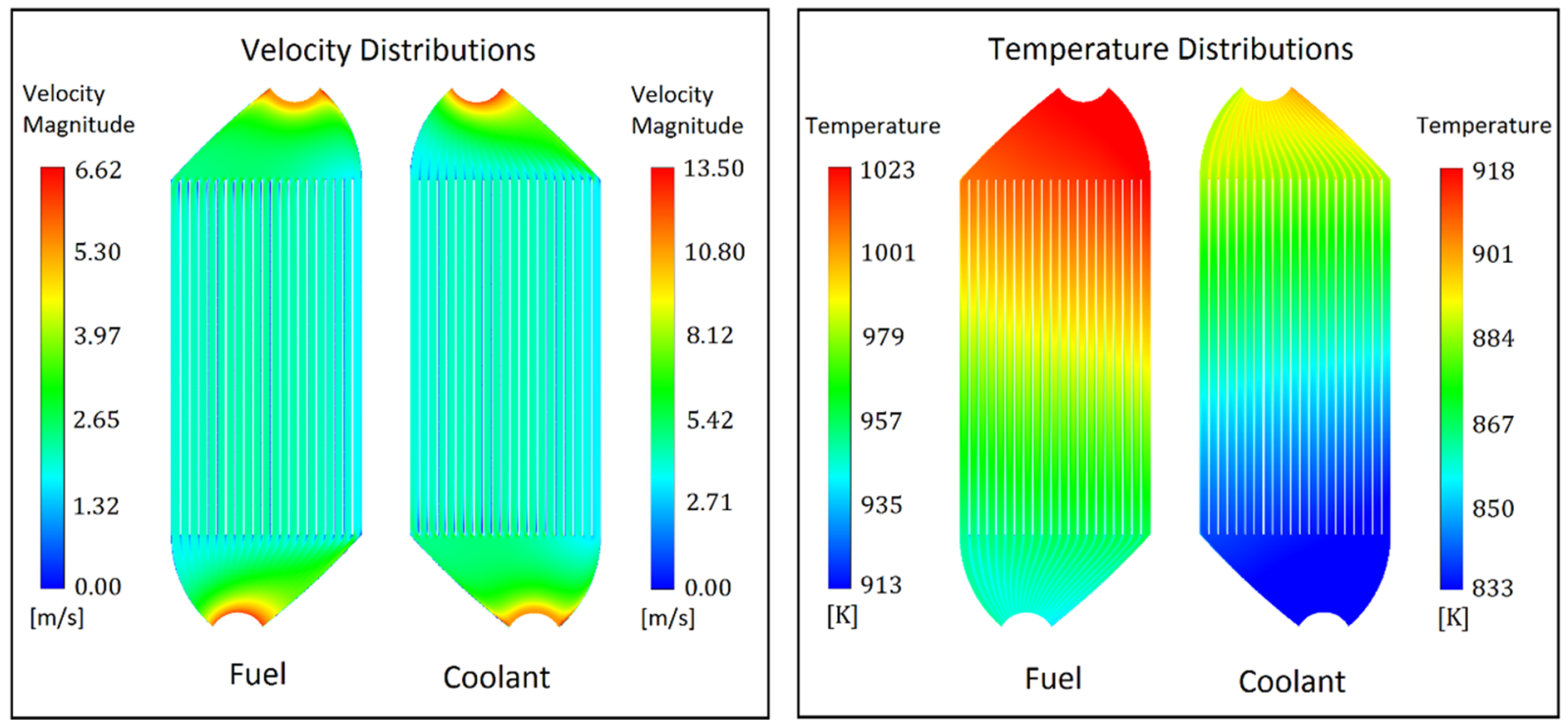

Fig. 5. Velocity and temperature distributions in the fuel channel and the coolant channel (total height is $1.97 \mathrm{~m}$, plate width is $0.7 \mathrm{~m}$, there are 20 pieces equally spaced separator).

In subsequent studies, it is recommended by the experts that the core outlet temperature will be below $750^{\circ} \mathrm{C}$ for MSRs due to the salt corrosion over the material $[26,27]$. Thus, the design criteria for heat exchanger design were further tightened, and studies continued for core outlet temperature (HX inlet fuel salt temperature) of around $750{ }^{\circ} \mathrm{C}$ and temperature drop of $75^{\circ} \mathrm{C}$. The adopted boundary conditions for the final design are given in Table 2 .

Previous studies were repeated on these boundary conditions. Both hydraulic and thermal design studies were performed for these conditions, and final geometric design is determined. Table 3 shows the geometric parameters and the results obtained. The results provided all the requirements. The temperature decrease amount in fuel side is obtained as $75^{\circ} \mathrm{C}$ which is adopted due to the design criteria. The minimum fuel salt temperature in the HX will be about $620^{\circ} \mathrm{C}$. The freezing temperature of the fuel salt is about $565^{\circ} \mathrm{C}$. Thus, there will not occur freezing region in the system. The coolant outlet temperature is about $620^{\circ} \mathrm{C}$. So, the temperature gradient across the plate is about $120^{\circ} \mathrm{C}$. Pressure drop is between 3 and 5 bar in the system. The dimensions of the heat exchanger giving these result are around $2.0 \times 1.5 \times 0.7 \mathrm{~m}(\mathrm{H} \times \mathrm{L} \times \mathrm{W})$. According to this system, the fuel volume in heat exchangers (16 heat exchanger) and collectors obtain around $6 \mathrm{~m}^{3}$.

Temperature and velocity distributions in the fuel channel and the coolant channel of the HX is presented in Figure 5. As shown in the figure, uniform flow distribution occurs in the system and temperature gradient across both channels is reasonable.

\section{Conclusion}

In this study, primary heat exchanger for MSR is designed taking reference to the predefined operating and boundary conditions. Since the compact HX is preferred, plate type
HX was selected. Both corrugated and flat plates were investigated and analyzed. Due to the occurrence of stagnation region in the HX, flat plate with separator was used for the design.

Firstly, to obtain uniform flow distribution, size and location of the collectors and separators were determined. Then, boundary conditions and geometric dimensions were optimized to meet the thermal requirements. There are several significant criteria in the design. For example, the temperature difference in the heat exchanger has to be $75^{\circ} \mathrm{C}$, the maximum velocity in the channel has not to exceed the limits, the total fuel volume in the heat exchanger has to be below the limits and the minimum temperature of the fuel salt will not lower than the freezing temperature.

The temperature of the fuel salt is adopted as about $750{ }^{\circ} \mathrm{C}$ at the inlet of HX. Coolant inlet temperature is adopted as about $560^{\circ} \mathrm{C}$. Fuel salt enters the HX from the top side and exits from the bottom side. On the other side, coolant salt enters the HX from bottom side and exits from the top side. Velocity of the fuel salt is about $5 \mathrm{~m} / \mathrm{s}$ in the collector region and $2.5 \mathrm{~m} / \mathrm{s}$ in the channel. Velocity of the coolant salt is about $10 \mathrm{~m} / \mathrm{s}$ in the collector region and $5 \mathrm{~m} / \mathrm{s}$ in the channel. Salt molar content and thermophysical properties of fuel $\left({ }^{7} \mathrm{LiF}-\mathrm{ThF}_{4}{ }^{2}{ }^{233} \mathrm{UF}_{3}\right)$ and coolant (LiF-NaF-KF) is adopted from reference study [25]. Hastelloy- $\mathrm{N}$ is used for plate material [28].

According to the calculations, a compact $\mathrm{HX}$ is designed. The height of HX is about $2.0 \mathrm{~m}$, total length is about $1.5 \mathrm{~m}$ and the width is $0.7 \mathrm{~m}$. Pressure drops for fuel and coolant channels were found as about 3 bar and 5 bar, respectively. The total fuel volume will be about $6 \mathrm{~m}^{3}$ in the HX unit (in channels and collectors). The HX provided the temperature drop of $75^{\circ} \mathrm{C}$ in coolant side. The minimum fuel temperature is obtained about $620^{\circ} \mathrm{C}$ in the HX channels. The resident time is obtained about $2 \mathrm{~s}$. 
The unreleased and commercial design data used in this study have been obtained through a delivery report of SAMOFAR project. Authors thank to the SAMOFAR project consortium for the valuable supports.

\section{Author contribution statement}

Uğur Köse is a research and application engineer at FİGES. He is a staff of Nuclear Technology Department with a specialization in nuclear thermal-hydraulics and nuclear safety fields. He created the manufacturable CAD model for HX and he performed CFD analyses to optimize the thermal performance of HX. Ufuk Koç is a research and application Engineer at FİGES. He is a staff of Nuclear Technology Department with a specialization in nuclear thermal-hydraulics and code development. He developed OD based code to simulate HX system using MATLAB toolboxes and he performed CFD simulations to optimize the hydraulic performance of HX. Latife Berrin Erbay is a professor at the Eskişehir Osmangazi University. She has experiences and publications of heat exchanger design and thorium molten salt reactors. She advised on the types and properties of HX based on her background. Erdem Ögüt is the Head of Additive Manufacturing Department at FİGES. He is an expert in mechanical properties of metals. He advised on manufacturability and strength of the designed geometry. Hüseyin Ayhan is a Manager of Nuclear Technology Department at FIGES. He specializes in nuclear reactor thermal-hydraulics, nuclear safety, advanced nuclear reactor design, fluid mechanics and heat transfer applications. He guided the course of the design, taking into account the criteria and constraints.

\section{References}

1. K. Furukawa, L.B. Erbay, A. Aykol, A study on a symbiotic thorium breeding fuel-cycle: THORIMS-NES through FUJI, Energy Convers. Manag. 63, 51 (2012)

2. K. Furukawa, K. Mitachi, S.E. Chigrinov, Y. Kato, A. Lecoco, L.B. Erbay, Rational Pu-disposition for 233 U-production by THORIMS-NES (Thorium Molten-Salt Nuclear Energy Synergetics), International Atomic Energy Agency Technical Document IAEA - TECDOC, 840, pp. 169-181, 1995

3. K. Furukawa et al., A road map for the realization of globalscale thorium breeding fuel cycle by single molten-fluoride flow, Energy Convers. Manag. 49, 1832 (2008)

4. K. Furukawa, L.B. Erbay, A study on a global scale symbiotic thorium breeding fueal cycle, in Proceedings $O f$ The 2nd International Conference On Nuclear And Renevable Recources NURER2010, 2010, pp. 255-261

5. K. Furukawa, D.E. Graves, L.B. Erbay, M. Hron, Y. Kato, New sustainable secure nuclear industry based on Thorium Molten-Salt Nuclear Energy Synergetics (THORIMS-NES), Nuclear Power - Deployment, Operation and Sustainability (InTech Open, London, 2011)
6. L.B. Erbay, Examining the power generation by the stirling heat engine combined with the Molten - Salt Reactor, in Proceedings Of International Symposium On Efficiency, Costs, Optimization, Simulation And Environmental Aspects Of Energy Systems: ECOS'99, 1999, pp. 429-434

7. S. Cantor, Density and viscosity of several molten fluoride mixtures, ORNL-TM-4308, 1973

8. D. Scott, A.G. Grindell, Components and systems development for molten-salt breeder reactors, ORNL-TM-1855, 1967

9. J.A. Lane, H.G. Macpherson, F. Maslan, Fluid fuel reactors (Addison-Wesley Company, Inc., Boston, 1958)

10. R.E. Macpherson, Gas cooled molten salt heat exchanger design study, ORNL-2605, 1958

11. C.W. Forsberg, Reactors with molten salts: options and missions, The 2004 Frédéric JOLIOT \& Otto HAHN Summer School - FJ/OH 2004, 2004

12. R.J. Kedl, C.K. McGlothlan, Tube vibration in MSRE primary heat exchanger, ORNL-TM-2098, 1968

13. C.E. Bettis et al., Design study of a heat-exchange system for one MSBR concept, ORNL-TM-1545, 1967

14. A.P. Fraas, A new approach to the design of design of steam generators for molten salt reactor power plants, ORNL-TM2953, 1971

15. F.H. Clark, O.W. Burke, Dynamic analysis of a salt supercritical water heat exchanger and trottle used with MSBR, ORNL-TM-2405, 1969

16. A.P. Fraas, M.E. LaVerne, Parametric survey of the effects of major parametres on the design of fuel-to-1nert-salt heat exchangers for the MSBR, ORNL-TM-2952, 1971

17. L.B. Erbay, Knowhow Of Th-MSR heat exchange system, in 11th International Conference On Sustainable Energy Technologies, 2012

18. V. Ariu, Heat exchanger analysis for innovative molten salt fast reactor, Master Thesis, Paul Scherrer Institute, 2014

19. Z. Pavel, V. Vaclav, Various methods to improve heat transfer in exchangers, EPJ Web of Conferences 92, 02119 (2015)

20. Project No: 249696, Final Report - EVOL project, 2014

21. J. Serp et al., The molten salt reactor (MSR) in generation IV: overview and perspectives, Prog. Nucl. Energy 77, 308 (2014)

22. M. Aufiero et al., Calculating the effective delayed neutron fraction in the Molten Salt Fast Reactor: Analytical, deterministic and Monte Carlo approaches, Ann. Nucl. Energy 65, 78 (2014)

23. S. Wang et al., A passive decay heat removal system for emergency draining tanks of molten salt reactors, Nucl. Eng. Des. 341, 423 (2019)

24. F.P. Incropera, D.P. DeWitt, T.L. Bergman, A.S. Lavine, Fundamentals of Heat and Mass Transfer (John Wiley \& Sons, Inc., 2007)

25. E. Merle-Lucotte et al., Preliminary design assessment of the Molten Salt Fast Reactor, in Proceedings of the ENC2012Advanced Reactors, 2012, pp. 17-26

26. V. Ignatiev, A. Surenkov, Material performance in molten salts (Elsevier Inc., Amsterdam, 2012)

27. V. Ignatiev, Materials and metals in MSR, in MSR Summer School, July 2-4, Lecco, Italy, 2017

28. Principle Features of Hastelloy-N. Available: https://www. haynesintl.com/alloys/alloy-portfolio_/Corrosion-resistantAlloys/hastelloy-n-alloy

Cite this article as: Uğur Köse, Ufuk Koç, Latife Berrin Erbay, Erdem Öğ̈̈t, Hüseyin Ayhan, Heat exchanger design studies for molten salt fast reactor, EPJ Nuclear Sci. Technol. 5, 12 (2019) 